\title{
US weapons test criticized
}

Washington

THE United States' successful testing of its controversial new anti-satellite (ASAT) weapon against a satellite target last week took place despite the attempts of four Democratic congressmen and the Union of Concerned Scientists (UCS) to prevent the test.

The congressmen, together with UCS, had asked a US District Court judge to block the test because, they alleged. President Reagan has not yet met a congressional requirement that he certify the United States is negotiating in good faith with the Soviet Union to reach an agreement on limiting anti-satellite weapons. The case was dismissed by the judge because it was a political matter that should not be determined by the court

The reaction from the Soviet Union to the test was predictably hostile: an embassy spokesman said the test would "inevitably entail negative consequences" for arms negotiations, especially since the Soviet Union has "exercised restraint" over ASAT weapons. The Soviet Union declared a moratorium on testing its own anti-satellite system two years ago but has threatened that a US decision to proceed with a satellite target test could lead to its own tests being re-started.

In its submission to the court last week, UCS included affidavits from two congressional observers at the US-Soviet arms control negotiations in Geneva. The observers testified that the United States has not responded to a Soviet proposal to ban testing of ASAT weapons, and that the United States has made no proposal of its own on the subject.

Critics of the test last week contend that it was conducted primarily for its political impact at Geneva, rather than for a genuine security need. The Soviet ASAT system is thought to be largely ineffective, and the target destroyed in last week's test was an out-of-service scientific satellite that was not properly instrumented to re lay details of the weapon's performance. Technical problems continue to hold up a dedicated target satellite that was originally planned for the test.

Another factor that may explain the administration's enthusiasm to press ahead with the test, according to UCS, is that the technology of the ASAT's miniature homing vehicle is relevant to the Strategic Defense Initiative (star wars). The miniature homing vehicle, which destroys its target by the force of its impact, contains sophisticated infrared sensors that track the target and computers which fire 56 small steering rockets (each one no more than once). One component of the star wars research programme calls for "space based kinetic kill vehicles" that would be launched by rockets from an orbiting battle station at missile re-entry vehicles; the sensor and steering technology involved would be essentially identical to that in the ASAT weapon.

UCS says, however, that last week's successful test against a single satellite should not be seen as evidence that a completely effective star wars missile defence is feasible. Most of the technical objec-

tions to such a system concern the difficulties of tracking large numbers of re-entry vehicles and of distinguishing real re-entry vehicles from decoys.

The ASAT weapon tested last week probably has an altitude range of no more than 700 kilometres, as UCS also points out, which would put only 16 Soviet satellites within range of the weapon.

UCS is considering an appeal against last week's dismissal of its case.

Tim Beardsley

\section{Supercomputers}

\section{UK machines oversubscribed}

"THE Americans are seeing shadows that we do not" is the attitude of British university researchers and computer centres to US pressure for restricting Eastern bloc access to supercomputers. More to the point, the issue is irrelevant: the small numbers of supercomputers available for research as well as the costs of bidding for time on them create a self-imposed restriction that renders US pressure unnecessary.

Britain has two regional centres, in London and Manchester, for university research involving supercomputers. Funding for these centres was originally justified by the cost-effectiveness of doing certain types of research on machines working at speeds in the gigaflop range. In the short time since the London Cray computer came on-line in 1983 and the Manchester Cyber in 1984, the centres have become oversubscribed. Even if a new supercomputer centre is set up at the Rutherford Appleton Laboratory (see Nature 316, 569; 1985), the original centres could quickly fill the additional capacity both are now seeking.

Researchers wanting time on one of the supercomputers are screened through their universities or Britain's research councils, which then place bids for supercomputer access. Any governmentimposed restrictions, therefore, would have to be aimed at all of Britain's universities, not just the two supercomputer centres, even though those centres make the final decisions about usage. Those lucky enough to be registered then use terminals in their own universities connected to the supercomputer (no instances are known of the password being broken). Time on the supercomputer, in other words, is so highly coveted that completing unauthorized work, particularly of any volume, on either machine is highly unlikely. The London and Manchester supercomputers are reserved for the use of the UK academic community and the work done on them, says Dr John Martin of the Manchester centre, has "no potential strategic implications whatsoever".

One possible avenue of US pressure is the inability of US companies, for whatever reason, to deliver computers on time or attempted imposition of restrictions on the machines' use. No restrictions or problems, says Dr Martin, were encountered during negotiations for the supercomputers already in place. "American companies are very keen to sell in Britain", says Dr Herbert of the Computer Board for Universities and Research Councils, and there is no evidence of intended pressure by US companies over machines for the proposed Rutherford centre. Nor is there any need for concern that supercomputer hardware will be resold outside Britain: such transfer, says Dr Herbert, "will never happen with supercomputers".

A concern of more relevance to university computer users, says Dr Martin, is the increased strength of restrictions placed by CoCom, the body coordinating Western high-technology export controls, on software produced either by universities or commercially. The blanket coverage of these restrictions is perceived as resulting in strict export limitations on software with no strategic implications at all.

Elizabeth Collins

\section{More than super}

According to recent reports in the Soviet media, the Soviet Union has developed a new "supercomputer", capable of performing 200 million operations a second (more than 10 times faster, it is claimed, than the US Cyber-73). The supercomputer, it is claimed, was developed entirely with Soviet resources, using a "basically new and more effective" data processing system, developed after the United States administration introduced restrictions on the sale of computers to the Soviet Union.

According to Moscow Radio (30 August), Western reports that the Soviet Union is lagging behind in electronics and computers are simply disinformation, circulated by those who seek to "discredit socialism and belittle its economic and scientific potential". Since electronics has become the key to industrial development, the commentator said, it must be clear to everyone that the Soviet Union, which accounts for one-fifth of the world's industrial production, cannot let itself be dependent on electronics imports.

Vera Rich 